\title{
Incorporating the Contextual Assessment Approach to regimens used in genetic family studies
}

\author{
Nedal H. Arar, $P h D^{1}$, Rosemarie Plaetke, $P h D^{1}$, Mazen Y. Arar, $M D^{2}$, Balakuntalam S. Kasinath, $M D^{1}$, and
} Hanna E. Abboud, $M D^{1}$

\begin{abstract}
Purpose: To develop a procedure that enhances enrollment and addresses ethical issues associated with participation in genetic family studies. Methods: The Contextual Assessment Approach (CAA) was standardized to the recruitment procedures in the Family Investigation of Nephropathy and Diabetes (FIND) study at the University of Texas Health Science Center at San Antonio. Structured interviews with the CAA questionnaire (CAA-Q) were conducted with 50 low-income Mexican-American probands. The CAA allows systematic interpretation of health beliefs, family dynamics, and attitudes regarding participation in FIND. Data analyses included qualitative and quantitative methods. Results: CAA analyses of probands' perspectives regarding relatives' enrollment in FIND facilitated recruiting 34 probands from whom 30 families were enrolled (family enrollment rate: $88 \%$ ). CAA reduced recruitment efforts by $32 \%$ and avoided exerting undue pressure on unwilling participants to ensure voluntary participation. Remarkably, $76 \%$ of the subjects were unaware of any risk associated with participation in genetic family studies. Conclusions: Administering the CAA-Q before enrolling subjects in FIND increased our enrollment rate by targeting efforts toward the willing subjects and addressing ethical issues associated with their participation. Genet Med 2002:4(6):451-463.
\end{abstract}

Key Words: genetic family studies, ethical issues, Contextual Assessment Approach

The prevalence of type 2 diabetes (T2DM) in Mexican Americans is two to three times higher than in the general population, predisposing them to develop diabetic nephropathy (DN) more than non-Hispanic whites. ${ }^{1} \mathrm{DN}$ (occurring mainly in adults) clusters in families with T2DM, suggesting that there is a genetic susceptibility for its development and progression. $^{2}$ The main goal of the Family Investigation of Nephropathy and Diabetes (FIND) study is to identify gene(s) involved in the development of DN (http://darwin.cwru.edu/ FIND). As a Participating Investigation Center in FIND, we are recruiting Mexican-American DN probands (first affected family member recruited into the study) with a family history of T2DM and their siblings and parents living in the San Antonio metropolitan area. FIND inclusion criteria include recruiting probands who have advanced nephropathy secondary to T2DM and have both living, willing parents or at least one sibling with $\mathrm{T} 2 \mathrm{DM}$ or $\mathrm{DN}$.

From the ${ }^{1}$ Division of Nephrology/Department of Medicine and ${ }^{2}$ Division of Nephrology/ Department of Pediatrics, University of Texas Health Science Center at San Antonio, Texas. The views expressed in this article are those of the authors and do not necessarily represent the views of any funding agency.

Nedal Arar, PhD, Assistant Professor of Medicine, Department of Medicine/Nephrology MC 7882, University of Texas Health Science Center at San Antonio, 7703 Floyd Curl Drive, San Antonio, TX 78229-3900.

Received: July 2, 2002.

Accepted: August 6, 2002.

DOI: 10.1097/01.GIM.0000036357.75294.32
The success of a genetic family study (GFS) depends on recruiters' ability to enroll a sufficient number of probands and their relatives. Enrollment of probands and select family members is influenced by a variety of factors including social, cultural, and ethical components. ${ }^{3}$ One important ethical issue is to ensure subjects' informed, voluntary consent prior to their participation in GFS. ${ }^{4}$ Understanding these factors will enhance enrollment and address ethical issues associated with participation in GFS. In this report, we introduce the Contextual Assessment Approach (CAA), a method that we found helpful while conducting 50 structured interviews with DN probands to evaluate and identify issues regarding family enrollment. The CAA allows systematic data collection that facilitates the interpretation of specific contextual patterns and meanings when attempting to enroll families. We will describe this new approach, explain how it enhances enrollment, and discuss its efficacy by presenting our experience and results based on interviews conducted with recruiters, DN patients, and their relatives.

\section{METHODS}

CAA was standardized to our recruitment procedures in the FIND study at the University of Texas Health Science Center at San Antonio (UTHSCSA). We conducted structured interviews using the CAA questionnaire (CAA-Q) with 50 low-income, Mexican-American probands and 69 relatives recruited from University Health System facilities in San Antonio, Texas. Administering the CAA-Q requires approximately 20 minutes. 
To ensure comparability of both English and Spanish questionnaires, translation-back translation methodologies were applied as described by Bernard. ${ }^{5}$ Three bilingual recruiters reviewed, discussed, and revised discrepancies. This version was then administered to five bilingual participants who indicated that they understood the questions in both languages. All subjects provided their informed consent before being interviewed; the institutional review board at UTHSCSA approved the study protocol and final versions of the CAA-Q.

Three focus group sessions were performed with four FIND recruiters at UTHSCSA to discuss their experience with the CAA, particularly their thoughts concerning efforts and time designated to enroll a family pre- and postadministration of CAA-Q.

\section{CAA evaluation}

We evaluated the efficacy of the CAA by using both qualitative and quantitative approaches, including (1) case examples (Appendix 1); (2) the use of weekly statistics forms to evaluate the effectiveness of the CAA in maximizing participation by comparing the number of families likely to be enrolled based on CAA evaluation to the number of families successfully enrolled in FIND (this form also supplies data on technical difficulties that might be encountered by recruiters, i.e., inaccuracies in reported telephone numbers, sample collections); and (3) calculating the enrollment rate and percent effort saved by the CAA as follows:

Percent effort saved by the CAA

$=$ (no. of probands with unwilling families) total no. of candidate probands) $\times 100 \%$

Enrollment rate of families by using CAA $=$ (no. of families enrolled) no. of probands recruited) $\times 100 \%$

\section{Data analysis}

Content analysis was applied to qualitative data generated through participant and recruiter interviews. We established a method for standardizing and displaying interview data, as described by Miles and Huberman, ${ }^{6}$ to analyze text using techniques from qualitative analysis, as discussed by Bernard. ${ }^{5} \mathrm{We}$ built initial matrices for each participant from blocks of text to identify trends among responses. Patterns were then summarized into higher-level matrices from which categories and themes were grouped together.

Descriptive statistics were performed (i.e., frequency distributions, mean, standard deviation, and range) on variables such as participants' age and years of education. Associations between variables in the form of contingency tables were examined by using a $\chi^{2}$ test. A Fisher exact test was used when the expected cell frequencies were small. We cross-checked all phases of analysis to determine how to apply coding categories and resolve any anomalies or discrepancies. Interrater reliability was established by validating consistency in coding and classification procedures by a second researcher recoding $50 \%$ of the case materials and checking for discrepancies. ${ }^{6}$ All data analyses were performed with SPSS. ${ }^{7}$

\section{RESULTS}

\section{A. CAA: Concept development}

CAA entails conducting structured interviews to explore the circumstances influencing subjects' opinions and attitudes toward participating in GFS. In structured interviews, all subjects are asked to respond to identical sets of questions to ensure that the output can be reliably compared. ${ }^{5} \mathrm{CAA}-\mathrm{Q}$ is composed of closed- and open-ended questions directed to explore health beliefs, family dynamics, and ethical issues associated with participation in FIND. Family dynamics are a special focus of the CAA because the family is the basic unit of analysis in GFS. Therefore, for the purpose of this report, family dynamics are regarded as the ongoing interpersonal interactions and relationships between family members (i.e., siblings and parents) that influence decisions regarding enrollment. ${ }^{8,9}$

The concept of integrating the CAA into regimens used in GFS resulted from performing several ethnographic studies. ${ }^{10,11}$ Previously, we conducted in-depth, semistructured interviews of open-ended questions with DN patients and their relatives (a subset of FIND participants) to explore their health beliefs about T2DM and DN and the associated ethical issues toward participation in GFS. Beliefs and attitudes are important distinct aspects of each culture and are essential for analyzing health-related behaviors. ${ }^{12,13}$ On the basis of participants' responses that emerged from these interviews, we quantified the interview data by developing closed-ended questions using theme-based coding categories which were representative of four or five response options. Participants selected the choice that best reflected their answer from which we classified several rising patterns that influenced probands' decisions to invite relatives to GFS. These patterns included (1) reporting close family relationships, (2) understanding the nature of the study, (3) enhancing awareness of the genetic nature of T2DM and DN, and (4) relatives' concerns about privacy and confidentiality. These patterns were tested, modified, and tailored to response options that best captured participants' answers in the CAA-Q. We then tested the questionnaire for contextual relevance (i.e., clarity, logic, and degree of importance for questions) by administering it to a select group of 10 ethnically diverse respondents and modifying it according to questions and responses that were best understood by FIND participants (mainly Mexican Americans). Several focus group interviews were also conducted with recruiters as an additional measure of instrument validity. ${ }^{6}$

CAA-Q is composed of three parts. The first set of questions is directed at collecting basic demographic data on participants such as gender, age, and educational level. These questions are important in the characterization of the study population to generate hypotheses regarding enrollment. The second part of the questionnaire is composed of 15 closed-ended and 4 openended questions formulated to gather data on subjects' health beliefs about T2DM and DN and to allow recruiters to establish 
trust and rapport with subjects. It also prompts relatives to consider family history as an important risk factor for developing DN. The third part of the questionnaire (12 closedended and 2 open-ended questions) examines two important themes: family dynamics and ethical issues associated with participants' decisions to participate in GFS (i.e., awareness of risks, disclosure of health information; see Appendix 2).

\section{B. The recruitment process}

The recruitment process with the CAA-Q is summarized in Table 1. Initial screening begins with a list of patients from dialysis units, renal clinics, and transplant clinics that recruiters screen for FIND inclusion criteria (i.e., DN diagnosis and a family history of diabetes; Fig. 1). Contrary to conventional recruitment regimens used in GFS (Table 1), probands meeting FIND inclusion criteria and agreeing to participate provide CAA consent to interview them in person or by telephone. The contextual analysis of subjects' perspectives, attitudes, and opinions concerning participation in the FIND study provides an understanding of factors influencing enrollment and allows for efficient reporting of information to determine what data are relevant and appropriate to the inference process. CAA evaluation will determine whether recruiters attempt to enroll potential probands and their relatives. Probands who indicate "family unwillingness" will not be enrolled in FIND even if they meet FIND inclusion criteria. On the other hand, we will attempt to enroll probands who reveal "family willingness" or who are "undecided" regarding their relatives' participation. In such cases, recruiters first ask probands to contact their relatives to assess whether they are willing to participate. If relatives agree, recruiters contact relatives and enroll them in FIND. Steps 3, 4, 5, and 8 are integrated into conventional GFS recruitment regimens as shown in Table 1.

\section{CAA-Q implementation (subjects' structured interviews)}

Of the $200 \mathrm{DN}$ patients screened at our local clinics, 50 $(25 \%)$ met FIND inclusion criteria and completed the CAA-Q.
Twenty-eight of the 50 were willing probands who reported having willing relatives, 6 were willing probands but undecided concerning their relatives' willingness to participate, and 16 were willing probands with unwilling relatives (Table 2).

We enrolled two families from the six willing probands who were undecided concerning their relatives' participation. Consequently, the total number of families enrolled was $30(28+$ 2 ). The total number of probands recruited for FIND was 34 $(28+6)$.

Enrollment rate of families by using CAA $=$ (no. of families enrolled $/$ no. of probands recruited) $\times 100 \%$

$$
(30 / 34) \times 100 \%=88 \%
$$

By using CAA, we excluded 16 families and saved time by not allocating efforts to recruit unwilling relatives.

Our percent effort effort saved by using the CAA $=$ (no. of probands with unwilling families/ total no. of candidate probands) $\times 100 \%$

$$
(16 / 50) \times 100 \%=32 \%
$$

CAA saved $32 \%$ of our recruiting efforts by excluding this subset of participants. Recruiters saved the time needed to enroll willing probands and time required to recruit unwilling relatives.

Multiple attempts to recruit members from the 16 "unwilling" families were carried out. We planned to follow up with 8 of the 16 willing probands who gave us permission to contact their relatives to validate their responses concerning relatives' participation. After numerous contacts with four probands (six follow-ups) and eight of their relatives (seven follow-ups), we were unsuccessful at recruiting family members. We elected not to follow any more cases for the following ethical and practical reasons: (1) we wished to avoid exerting unnecessary pressure on probands and their relatives to the extent that participation becomes involuntary, (2) the CAA has

Table 1

Recruitment and enrollment of families at the San Antonio Center of FIND and application of the CAA

Recruitment process using CAA

1. Identify potential probands (DN patients)

2. Screen potential participants using Pedigree Screening Form to assess FIND phenotypic inclusion criteria

3. If participants meet FIND phenotypic inclusion criteria, obtain consent for the CAA-Q

4. Administer the CAA-Q

5. Evaluate participants' responses for possibility of enrolling family members

6. Obtain consent for enrollment into FIND if CAA evaluation reveals possibility of family enrollment

7. Enroll probands in FIND; schedule date for collection of specimen, completion of FIND questionnaires, and shipping samples to NCI

8. Contact relatives through probands, recruit them, apply the CAA-Q, and review release of confidentiality to obtain medical records

9. Schedule date for specimen collection from relatives, completion of the medical questionnaire, ship samples to NCI and enter data into FIND database

NCI, National Cancer Institute. 
Date:

Name:

Phone Number: ( )

Gender:

Ethnicity:

Age:

Clinic/Unit:

FIND/phenotypic inclusion criteria

Yes No Maybe

Reason:
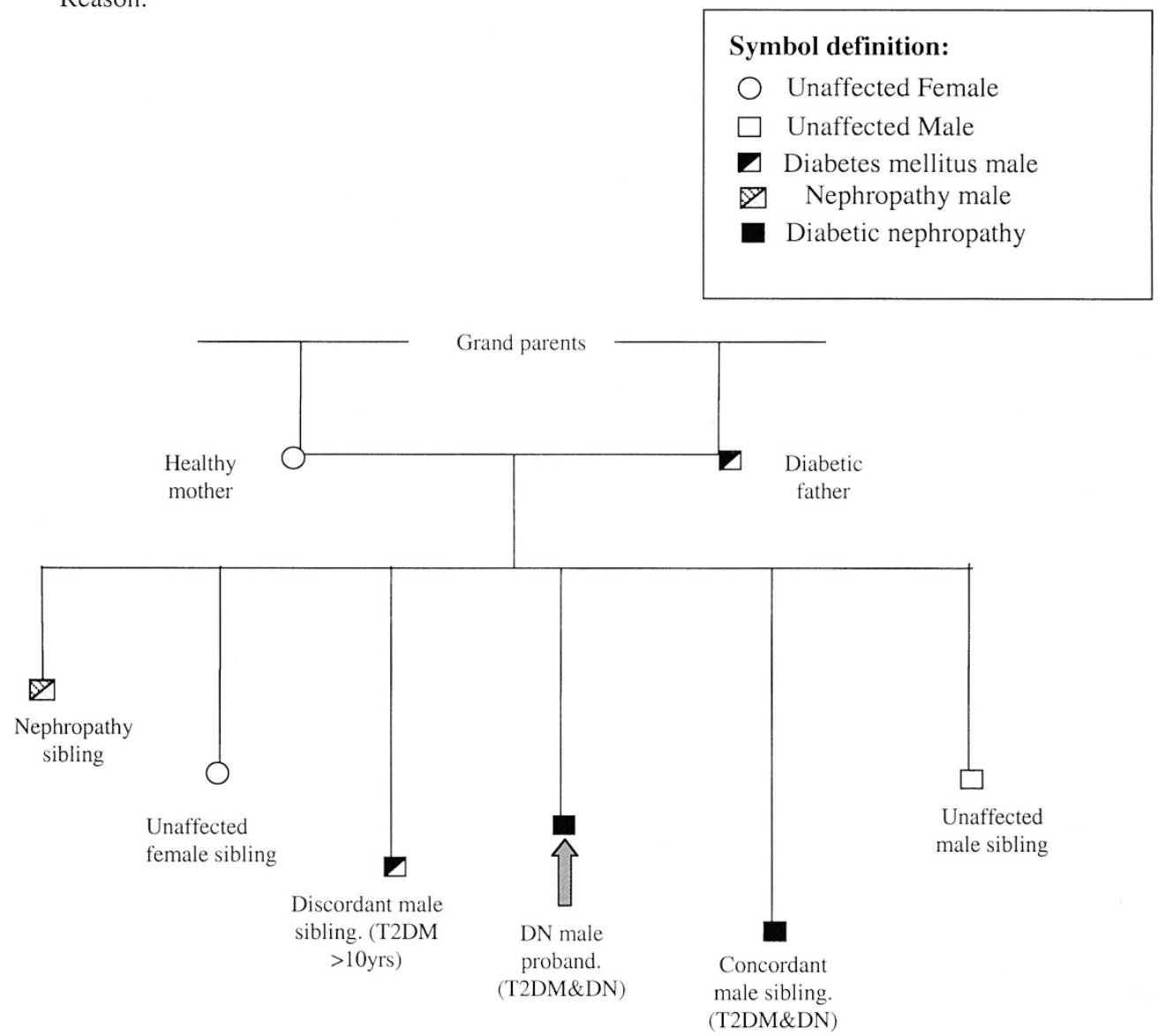

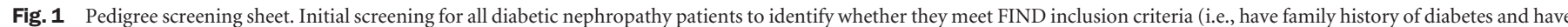
a sibling with diabetes or diabetic nephropathy).

clearly identified important factors affecting family participation, and (3) recruiting unwilling relatives is very tedious, time-consuming, and unlikely to materialize based on our previous experience.

\section{D.1. Sociodemographic characteristics of subjects}

The CAA was administered to 119 subjects, 50 FIND Mexican-American DN probands on dialysis and 69 relatives. Fiftyeight percent of the subjects were female, with an average age of 54.2 years (range: $33-76, S D=9.04$ ). The majority of our study population reported having at least two generations of Mexican ancestry (90\%), with only $10 \%$ born in Mexico but permanently residing in the United States. Two thirds had a high school education or less. Eighty-four percent of the probands had a yearly household income $\leq \$ 20,000$ compared with $48 \%$ of their relatives (Table 3). Analysis of association revealed a higher percentage of females (73\%) among enrolled relatives ( $\chi^{2}$ test, $P \leq 0.05$; Table 3 ). This observation infers that there is

Table 2

Probands' responses concerning family participation based on CAA evaluation

\begin{tabular}{lccccc}
\hline & \multicolumn{2}{c}{$\begin{array}{c}\text { Probands } \\
(n=34)\end{array}$} & & \multicolumn{2}{c}{$\begin{array}{c}\text { Families enrolled } \\
(n=30)\end{array}$} \\
\cline { 2 - 3 } \cline { 5 - 6 } Willing probands with: & Frequency & $\%$ & & Frequency & $\%$ \\
\hline Willing relatives & 28 & 82 & & 28 & 93 \\
Undecided relatives & 6 & 28 & & 2 & 7 \\
Total & 34 & 100 & & 30 & 100 \\
\hline
\end{tabular}


Table 3

Sociodemographic characteristics of probands and relatives

\begin{tabular}{|c|c|c|c|c|c|c|}
\hline & \multicolumn{2}{|c|}{ Probands $(n=50)$} & \multicolumn{2}{|c|}{ Relatives $(n=69)$} & \multicolumn{2}{|c|}{ Total $(n=119)$} \\
\hline & Frequency $^{a}$ & $\%$ & Frequency $^{a}$ & $\%$ & Frequency $^{a}$ & $\%$ \\
\hline \multicolumn{7}{|l|}{ Education } \\
\hline High school or below & 37 & 74 & 45 & 65 & 82 & 69 \\
\hline College (2-4 years) & 12 & 24 & 11 & 16 & 23 & 19 \\
\hline Graduate & 1 & 2 & 0 & 0 & 1 & 1 \\
\hline No response & 0 & 0 & 13 & 18 & 13 & 11 \\
\hline \multicolumn{7}{|l|}{ Gender } \\
\hline Female & 19 & 38 & 50 & 73 & 69 & 58 \\
\hline Male & 31 & 62 & 19 & 27 & 50 & 42 \\
\hline \multicolumn{7}{|l|}{ Income/household } \\
\hline$\leq \$ 10,000$ & 22 & 44 & 18 & 26 & 40 & 34 \\
\hline$>\$ 10,000 \leq \$ 20,000$ & 20 & 40 & 15 & 22 & 35 & 30 \\
\hline$>\$ 20,000 \leq \$ 30,000$ & 3 & 6 & 10 & 14 & 13 & 11 \\
\hline$>\$ 30,000$ & 1 & 2 & 6 & 9 & 7 & 6 \\
\hline No response & 4 & 8 & 20 & 29 & 24 & 20 \\
\hline \multicolumn{7}{|l|}{ Health status } \\
\hline $\begin{array}{l}\text { End-stage renal disease due to } \\
\text { diabetes/probands }\end{array}$ & 50 & 100 & - & - & 50 & 43 \\
\hline Early-stage diabetic nephropathy & - & - & 35 & 51 & 35 & 29 \\
\hline T2 DM & - & - & 14 & 20 & 14 & 11 \\
\hline Healthy & - & - & 20 & 29 & 20 & 17 \\
\hline
\end{tabular}

${ }^{a}$ Absolute frequency.

a significant gender difference in relatives' attitudes toward enrollment that warrants further investigation (manuscript in preparation). We have also studied the relationship between relatives' attitudes toward participating in FIND and their age, level of education, and income. No significant differences were observed. This may be due to the fact that our sample size is relatively small. An increased variation in responses may result from a larger sample of subjects of different ethnicities.

\section{D.2. Health beliefs}

CAA-Q explored DN patients' and their relatives' health beliefs concerning the clustering of T2DM and DN. Data revealed many similarities between patients' and relatives' thoughts about T2DM and DN clustering ( $\chi^{2}$ test; $P>0.05$ ). The majority of participants $(n=76,64 \%)$ perceived T2DM to run in their family; only $36 \%(n=43)$ believed that $\mathrm{DN}$ ran in their family. Ninety-two percent $(n=110)$ of the subjects indicated that they were willing to provide information about the clustering of T2DM in their families, whereas $8 \%(n=9)$ did not agree.

\section{D.3. Ethical issues}

Family relationship was one important factor that influenced probands' decisions regarding relatives' enrollment in
FIND. Sixty-three percent of willing probands were reluctant to contact their relatives because they felt they did not have good relationships with them (Table 4). CAA promotes relatives' voluntary participation by exploring and asking specific questions related to family dynamics and relationships. For example, the CAA was administered to a 28-year-old proband who reported having a brother with T2DM and four healthy siblings. The proband stated, "Although I would like to contact them [siblings], they will not participate." Further probing revealed that his siblings would feel that researchers would test them for kidney compatibility for a donation. The proband

Table 4

Factors affecting family participation in FIND

\begin{tabular}{lcr}
\hline & \multicolumn{2}{c}{$\begin{array}{c}\text { Willing probands with unwilling } \\
\text { families }(n=16)\end{array}$} \\
\cline { 2 - 3 } & Frequency & $\%$ \\
\hline Poor family relationship & 10 & 62 \\
Concerns about privacy & 4 & 25 \\
Sick relatives & 2 & 13 \\
Total & 16 & 100 \\
\hline
\end{tabular}


disclosed that kidney donation was a sensitive issue within the family and that it was a source of tension. Through administering the CAA-Q and building rapport with this proband, recruiters were able to identify this sensitive issue. CAA identifies and addresses the degree to which researchers should pursue recruiting relatives to ensure voluntary participation.

Furthermore, CAA-Q explores subjects' awareness of some of the risks associated with participation in GFS to ensure that subjects are informed when they consent to participate. Examples of such risks include (1) the disclosure of health and identifiable information regarding relatives without their prior knowledge and (2) confidentiality and privacy of genetic information. Seventy-six percent $(n=90)$ of our participants stated that there were no risks associated with participation compared with only $10 \%(n=12)$ who felt that there were. Fourteen percent $(n=17)$ of our participants reported that they did not know whether or not there were any risks (manuscript in preparation). Therefore, when enrolling subjects in FIND, recruiters spend additional time to explain thoroughly the risks associated with participation in GFS/FIND as they obtain subjects' consent.

\section{DISCUSSION}

An understanding of subjects' opinions and attitudes toward participation in GFS will maximize enrollment and address subjects' needs. ${ }^{14}$ Incorporating the CAA into regimens used in GFS entails conducting structured interviews to explore the circumstances influencing subjects' attitudes toward participating in GFS. The CAA focuses on participants' perspectives because the initiation, implementation, and evaluation of the enrollment process are based on the contextual analysis of participants' health beliefs, family dynamics, and ethical issues associated with the enrollment. Once probands meet inclusion criteria, recruiters can apply the CAA to assess probands' attitudes toward participation and inviting their relatives. Correspondingly, Trauth et al. ${ }^{14}$ examined public attitudes regarding willingness to participate in medical research studies. They found that almost half of the respondents were willing, while one third were undecided. They suggested that researchers enhance participation by inviting those subjects identified as willing to participate in studies.

Enrolling probands in GFS generally requires less time and effort than enrolling their relatives. ${ }^{10}$ As illustrated in Case 3 (Appendix 1), without the CAA, a significantly larger amount of time is spent on recruitment of probands who are unsuccessful at inviting their relatives. Our results indicate that at least one third of our probands fit this profile. By excluding this subset of participants, the CAA saves nearly $32 \%$ of recruitment efforts and ensures voluntary participation. CAA enhances and addresses ethical issues associated with subjects' participation in GFS for the following reasons:

1. CAA explores factors and concerns affecting participation such as family dynamics and probands' relationships with their relatives (Case 1, Appendix 1). Our participants' concerns were consistent with those raised in research related to GFS, yet different from concerns associated with research studies that are clinical in nature. The inherent difference in GFS results from the shift in focus from the traditional model of an individual to that of a family model. In the family studies model, (1) subjects have ties to other research participants through shared genetic heritage, (2) information learned from the research may affect the entire family, and (3) family members may become part of the study without their consent. ${ }^{15}$ Some of our probands were reluctant to contact relatives because they (1) do not have a good relationship or (2) have concerns about privacy and confidentiality. Probands indicated that if they supply lists of family members for researchers to contact, relatives might feel that their privacy is invaded. Therefore, by applying the CAA before enrolling subjects into GFS, recruiters spend additional time to thoroughly explore and address concerns and risks associated with participation in GFS/FIND as they recruit and obtain consent for all members of a family. Similarly, Parker ${ }^{16}$ indicated that enrollment in GFS can involve researchers pressuring probands to contact their relatives, resulting in their involuntary participation. Consequently, researchers should aim to minimize pressure on participants by applying a preventive ethics approach to recognize potential ethical conflicts and prevent them from arising.

2. Another ethical issue identified in this report is our subjects' pervasive lack of awareness regarding risks associated with participation in GFS. While discussing potential risks such as discrimination in the workforce and health insurance, subjects did not consider these issues to influence their decision to participate in GFS. Individuals who are unaware of their risks cannot provide informed consent when participating in a study. Potential enrollment in genetic research is affected by subjects' knowledge about the risks associated with their participation..$^{4,16}$ Unlike research in which the risks are primarily physical, in our study the primary physical risk, drawing blood, is negligible in comparison with the potential magnitude of social, economic, and psychological harms. For this reason, effective communication and broadening the perspective to include the family unit are crucial components in ensuring that informed decisions to participate in GFS are made. This report stresses the importance of incorporating CAA to GFS recruitment regimens used among a low-income minority Mexican-American population. This assessment enables recruiters to explore potential risks associated with subjects' participation by asking specific questions about the disclosure of health and identifiable information on relatives and issues related to confidentiality and privacy of genetic information to ensure informed consent before enrolling them in FIND. Future publications will discuss such ethical issues in more detail (Arar et al., American Society of Human Genetics, October 2002).

3. CAA also explores participants' health beliefs and enhances their awareness of the genetic nature of DN and T2DM, especially among at-high risk healthy relatives. Contrary to common beliefs about Mexican Americans' use of alternative treatment and curanderos (traditional healers) for the treatment of diabetes, we found that in our study population, bio- 
medical treatments were the preferred treatment. Consequently, traditional attitudes and beliefs did not present any barriers for treatments. ${ }^{12}$ The CAA-Q encourages participants to learn about T2DM and DN while stimulating them to think about family history as an important risk factor to promote participation in GFS and consider preventive measures. This aspect of the CAA is very important because $53 \%$ of FIND diabetic relatives have unknowingly already developed kidney problems and about 30\% of "healthy" participants are not aware of having diabetes. Similar to our investigation, Kreiger et al. ${ }^{17}$ found that potential participants' knowledge about the genetic nature of a disease influences their decisions toward participation. However, willingness to participate in FIND was not only influenced by participants' beliefs about the clustering of T2DM and DN. Other factors such as family relationships seemed to be equally important in determining family participation (refer to Cases 1 and 2, Appendix 1). While our study addresses a population affected by a common complex disease (T2DM) caused by both environmental and genetic factors, health beliefs regarding monogenic diseases (i.e., cystic fibrosis) caused by genetic factors might have a greater impact on participation and the disclosure of health information by family members.

4. In addition, CAA enhances the interaction between recruiters and participants by allowing recruiters to establish rapport and trust with subjects (for more information about recruiters' perspective refer to http://darwin.cwru.edu/FIND). Recruiters learn to identify the "key informant" of a family, who is usually responsible for issues related to his/her family. Identifying a "key informant" facilitates contact between recruiters and families, thus enhancing the study's enrollment outcome. In addition, probands feel that recruiters are involving them in the study by exploring their opinions regarding diabetes and kidney disease as opposed to enrolling them and providing financial compensation for their samples. By establishing rapport with subjects, recruiters better understand factors influencing subjects' participation, evaluate probands' attitudes toward enrollment, and direct recruitment efforts toward willing families (see Case 2, Appendix 1). Similarly, Foster et al. ${ }^{18}$ suggested that understanding the relevant decision-making units in a society will permit investigators to identify appropriate representatives who can promote discourse with the community and enhance subjects' participation in GFS. Using the CAA before enrolling subjects in GFS will build trust and facilitate rapport with subjects. Initial contact with probands will, to a large extent, dictate the ability to contact relatives. Similarly, Kreiger et al. ${ }^{17}$ conducted several focus group sessions to build an understanding of concerns that probands and their relatives have about participating in GFS. Subjects were more likely to participate in GFS when rapport was established with recruiters. These results substantiate previous findings about enrollment strategies that stress the importance
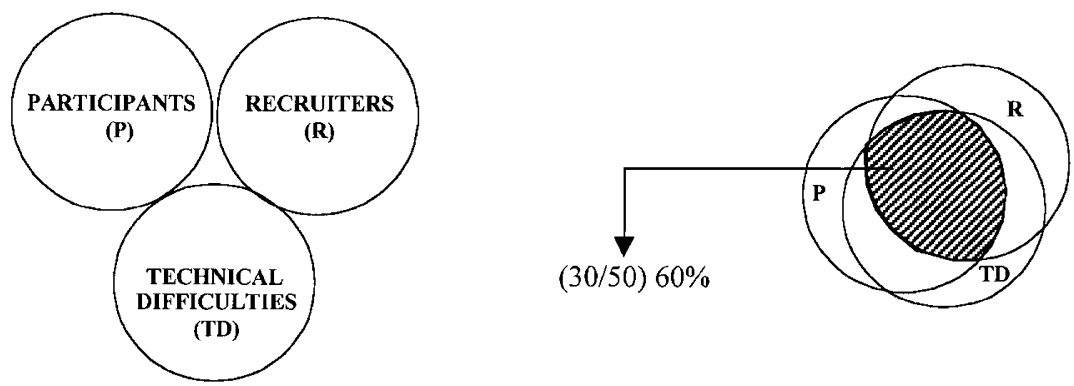

Domains Affecting the Enrollment Process $\quad$ Enrollment Process Without Using the CAA (30/50) 60\%

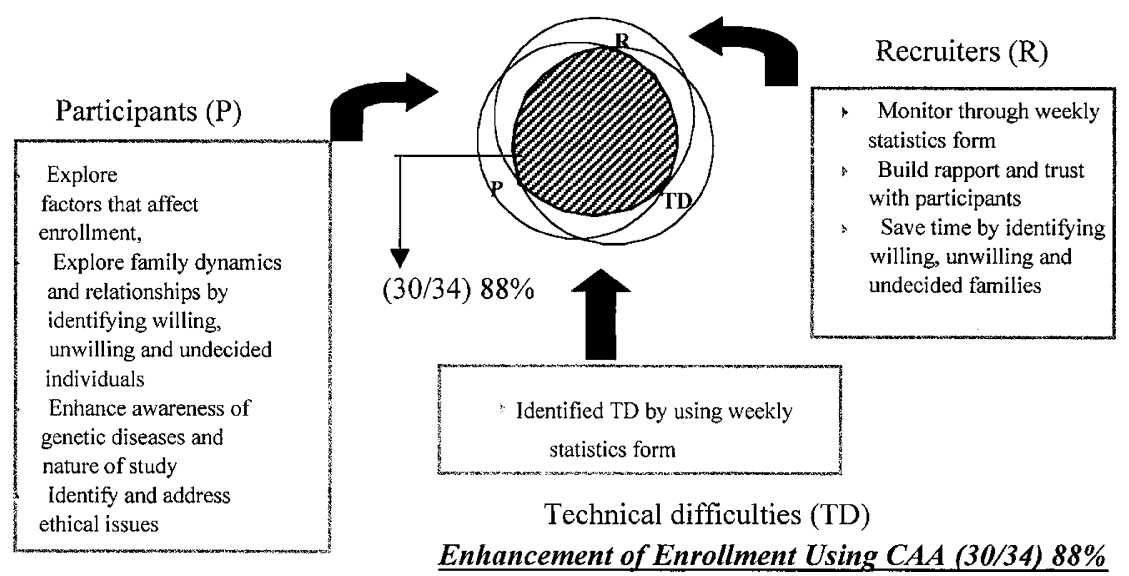

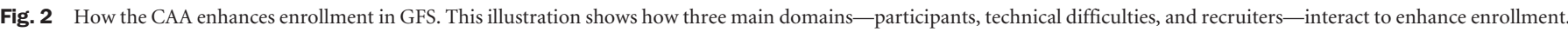
The CAA enhances enrollment by expanding the overlap area among these three domains, particularly to improve the interaction between recruiters and participants. 
of establishing communication between recruiters and study participants. ${ }^{10}$

5. Finally, successful enrollment is established from interactions between three domains: participants, recruiters, and technical difficulties. Figure 2 shows how these domains interact to enhance enrollment. The CAA improves enrollment by expanding the overlap area among domains and enhancing family participation, monitoring recruiters, and identifying technical difficulties encountered in the field. In particular, CAA improves the interaction between recruiters and participants and allows systematic data collection to reveal the factors that influence participation in GFS.

While the broader implications of this approach remain to be verified, we believe CAA will prove to be especially useful when conducting GFS among low-income minority MexicanAmerican populations to ensure informed decisions to participate and successful enrollment of families. This approach is generalizable to the extent that the questionnaire is tailored to capture ethical concerns within the cultural and socioeconomic context of the population being studied. Our intention in this report is not to generalize current findings to include all subjects participating in GFS but to present and describe an approach that we have found helpful when evaluating and identifying issues that influence enrollment. Additional studies among larger populations and other ethnic minority groups should be performed in the future.

\section{Acknowledgments}

This work was funded by ELSI/NIH (1 R03 HG 02 381); South Texas Veterans Health Care System, San Antonio, Texas; and an Institutional Research Grant from UTHSCSA for N. Arar. The ascertainment of families was funded by NIDDK/ NIH, Family Investigation of Nephropathy and Diabetes, 5 U01 DK57295. The authors thank Dr. Helen Hazuda for her thoughtful comments.

\section{References}

1. Stern MP, Mitchell B. Diabetes in Hispanic Americans. In: National Diabetes Data Group and National Institute of Diabetes and Digestive and Kidney Disease, editors. Diabetes in America, 2nd ed. Bethesda, MD: National Diabetes Information Clearinghouse, 1995:631-659.

2. Krowlewski AS. Genetics of diabetic nephropathy: evidence for major and minor gene effect. Kidney Int 1999;55:1582-1596.

3. Bonicini KA. The art of recruitment: the foundation of family and linkage studies of psychiatric illness. Fam Process 1998;37:153-165.

4. Office for Protection From Research Risks and National Institutes of Health. Institutional review board guidebook. Washington, DC: US Government Printing Office, 1993.

5. Bernard HR. Research methods in cultural anthropology. Newbury Park, CA: Sage Publications, 1990.

6. Miles M, Huberman AM. Qualitative data analysis: An expanded source book, 2nd ed. Thousand Oaks, CA: Sage Publications, 1994.

7. Norusis MJ. SPSS, release 9.1. Chicago: SPSS Inc, 2000.

8. Holder B, Turner-Musa J, Kimmel PL, Alleyne S, Kobrin S, Simmens S, Cruz I, Reiss D. Engagement of African American families in research on chronic illness: a multisystem recruitment approach. Fam Process 1998;37:127-151.

9. Norden K, Klein DN, Ferro T, Kasch K. Who participates in a family study? Compr Psychiatry 1995;36:199-206.

10. Arar NH, Sarosdy M, Thompson I, Troyer D, Shepherd D, Plaetke R. Risk perceptions among patients and their relatives regarding prostate cancer and its heredity. Prostate Cancer Prostatic Dis 2000;3:176-185.
11. Arar NH, Plaetke R, Hazuda H, Duggirala R, Pergola P, Kasinath B, Stern M, Abboud $\mathrm{H}$. Cultural and ethical issues associated with subjects' participation in genetic family studies [abstract]. Am J Hum Genet 2000:A(1113).

12. Hunt L, Arar N, Akana L. Herbs, prayer and insulin: use of medical and alternative treatments by a group of Mexican American diabetes patients. J Fam Pract 2000;49: $216-223$.

13. Kleinman A. Patients and healers in the context of culture: An exploration of the borderland between anthropology, medicine, and psychiatry. Berkeley: University of California Press, 1980.

14. Trauth JM, Musa D, Siminoff L, Jewell RK, Ricci E. Public attitudes regarding willingness to participate in medical research studies. J Health Soc Policy 2000;12:23-43.

15. Bennent R. The practical guide to the genetic family history. New York: Wiley-Liss Publications, 1999.

16. Parker L. Ethical concerns in the research and treatment of complex disease. Trends Genet 1995;11:520-523.

17. Kreiger N, Ashbury F, Cotterchio M, Macey J. A qualitative study of subject recruitment for familial cancer research. Ann Epidemiol 2001;11:219-224.

18. Foster M, Bernsten D, Carter T. A model agreement for genetic research in socially identifiable populations. Am J Hum Genet 1998;63:696-702.

\section{Appendix 1. Cases represent recruiters' experiences with the CAA}

Case 1. Gain more insight into family dynamics. A 54-year-old Mexican-American DN patient indicated that she had a diabetic sibling living in San Antonio. The proband was willing to participate in FIND and stated that her sibling might participate. CAA revealed that the sibling was in poor health and that the patient had not seen her in more than 5 years. Although the subject was interested in participating, she was unsure of how to contact her sibling. Analysis: The CAA provided important insight into family dynamics that contributed toward building rapport with the subject. Through conventional recruitment regimens, this proband would have been enrolled because she fulfilled FIND inclusion criteria and was willing to participate. The challenge to enroll her sibling was identified only after administering the CAA-Q and establishing rapport and trust.

Case 2. Identify "key informants" and address ethical issues related to participation. The candidate proband was a 53-yearold Mexican-American DN patient who underwent a kidney transplant; he had 21 siblings. CAA revealed that relationships between siblings had been severed since their mother's death. Probing regarding other family members (wife, cousins, aunts, uncles) who might qualify for the study revealed that the candidate proband's wife suffered from DN. The wife became our "key informant" because she happened to be the person who planned and organized family activities among relatives. She provided us with information regarding her family. She had 14 siblings, 9 of whom were diabetic; 7 of her siblings lived in San Antonio. We administered the CAA-Q to the wife and consequently enrolled her and her family. Analysis: The CAA adds a unique dimension to the enrollment process by identifying ethical issues when participants' thoughts are further explored. Specifically, CAA data indicated that we would not be able to recruit the candidate proband's relatives because he did not have a good relationship with them. In this regard, we avoided exerting undue pressure on him and allocate our efforts to his wife's family to ensure voluntary participation when it became apparent that she and her family qualified. 
Case 3. Reduce recruiters' time and efforts. The proband was a 44-year-old dialysis patient with five siblings, two of whom were diabetic. The proband was recruited because she seemed willing to participate and agreed to invite her siblings to FIND. CAA-Q was not administered to her prior to her enrollment. The proband was contacted on numerous occasions regarding her siblings' participation, and she maintained that they would be willing to participate. After several vigorous follow-up attempts, she stated that she spoke to them only once a month.
This case was finally closed after 3 months, leaving us with an incomplete family. Analysis: This case is representative of at least one third of the probands interviewed during previously conducted ethnographic studies. ${ }^{8,9}$ After numerous attempts to recruit her family, the patient revealed that she had little interaction with her siblings. By identifying and excluding this subset of probands, recruiters optimize their efforts by enrolling families as opposed to willing probands with unwilling relatives.

\section{Appendix 2. Contextual Assessment Approach Questionnaire}

Please, do not write in the boxes

Patient ID Number:

Proband:

Relationship to the proband:

Date:

Please, provide us with the following information about yourself

Name:

Address:

Telephone: Home: ( ） Work: ～）

\section{I-Demographic Information}

1. Your age is

2. Your gender is $1 . \square$ Male

2. $\square$ Female

3. You consider yourself to be

1. $\square$ African-American

2. $\square$ Anglo-American

3. $\square$ Asian-American

4. $\square$ Mexican-American

5. $\square$ Native-American

6. $\square$ Other, specify

4. At the present time, what is your household income (check only one category)

1. $\square$ Less than $\$ 10,000$

2. $\square \$ 10,000-\$ 20,000$

3. $\square \$ 20,000-\$ 30,000$

4. $\square \$ 30,000-\$ 40,000$

5. $\square$ More than $\$ 40,000$

5. Your highest educational degree is

1. $\square$ High school or below

2. $\square$ Technical school

3. $\square$ College (no degree)

4. $\square$ College degree

5. $\square$ College graduate

6. You current work sector is:

1. $\square$ State/Government

2. $\square$ Military

3. $\square$ Private sector

4. $\square$ Retired

5. $\square$ Unemployed (due to disability)

5. $\square$ Unemployed (not due to disability)

6. $\square$ Homemaker

7. Number of adults/children living in your household is 
8. Your marital status is:

1. $\square$ Married

2. $\square$ Single

3. $\square$ Widowed

4. $\square$ Divorced

5. $\square$ Separated

6. $\square$ Other, specify

9. With respect to your health status, would you say that you have:

1. $\square$ Diabetes and kidney disease

2. $\square$ Only diabetes

3. $\square$ Neither diabetes nor kidney disease

4. $\square$ Kidney disease only

5. $\square$ Other, specify

\section{Health Beliefs Concerning Diabetes and Its Kidney Complications}

We would like to ask you what you think about diabetes and kidney disease. In the following questions, we do not wish to test your scientific knowledge or what you have learned during your visits at the clinic. Therefore, feel free to be as open as possible in discussing your opinions.

1. Would you say that diabetes is a serious health problem?
$\square$ No
$\square$ Yes

If yes, diabetes is a serious health problem because

1. $\square$ Many relatives have it in your family

2. $\square$ Many people have it

3. $\square$ It has psychological/emotional impact

4. $\square$ Patients do not know of the disease until it is too late

5. $\square$ Causes changes in lifestyle

6. $\square$ Has many complications (causes other health problems)

7. $\square$ Other, please, specify

2. Which of the following would you say is caused by diabetes? (check all possible answers)

1. $\square$ Eye disease

2. $\square$ Heart or circulatory problems

3. $\square$ Impotence

4. $\square$ Kidney disease

5. $\square$ Nerve damage

6. $\square$ Fatigue

7. $\square$ Amputations

8. $\square$ Other, specify

3. Would you say that diabetes could cause kidney disease?
1. $\square$ Yes
2. $\square$ No
3. $\square$ I do not know

4. Would you say that kidney disease (secondary to diabetes) is a serious health problem?

$\square$ No $\square$ Yes

If yes, kidney disease (due to diabetes) is a serious health problem because:

1. $\square$ One can die

2. $\square$ Causes other health problems

3. $\square$ It affects the emotional and psychological well-being

4. $\square$ Patients do not know of the disease until it is too late

5. $\square$ It can impose permanent changes in lifestyle

6. $\square$ Kidneys are important part of the body

7. $\square$ I don't know

8. $\square$ Other, specify 
5. How would you compare diabetes and kidney disease?

1. $\square$ Diabetes is more serious than kidney disease

2. $\square$ Diabetes is less serious than kidney disease

3. $\square$ Diabetes is as serious as kidney disease

4. $\square$ I do not know

6. Do you think people of all ages have the same risks of getting diabetes?
1. $\square$ Yes
2. $\square$ No
3. $\square$ I do not know

7. Do you think men and women have the same risks of getting diabetes?
1. $\square$ Yes
2. $\square$ No
3. $\square$ I do not know

8. Do you think men and women have the same risks of getting kidney disease?
1. $\square$ Yes
2. $\square$ No
3. $\square$ I do not know

9. Do you think diabetes

1. $\square$ More common among Mexican Americans compared to the rest of the population

2. $\square$ More common among African Americans compared to the rest of the population

3. $\square$ More common among Native Americans compared to the rest of the population

4. $\square$ No difference

5. $\square$ I do not know

10. Do you think kidney disease (due to diabetes) is?

1. $\square$ More common among Mexican Americans compared to the rest of the population

2. $\square$ More common among African Americans compared to the rest of the population

3. $\square$ More common among American Indians compared to the rest of the population

4. $\square$ There is no difference among different population

5. $\square$ I do not know

11. If you are diabetic, how did you first find out that you have diabetes?

12. What are the signs and symptoms associated with diabetes?

13. If you have kidney disease, how did you first find out that you have kidney disease due to diabetes?

14. What are the signs or symptoms associated with kidney disease that is caused by diabetes?

15. What do you think are the causes of diabetes?

1. $\square$ Heredity

2. $\square$ Food, specify

3. $\square$ Medications

4. $\square$ Alcohol

5. $\square$ Stressful life

6. $\square$ Stress, specify

7. $\square$ Overweight

8. $\square$ Hot/cold

9. $\square$ I don't know

16. What do you think are the causes of kidney disease that occurs in diabetic patients?

1. $\square$ Heredity

2. $\square$ Diabetes

3. $\square$ High blood pressure

4. $\square$ Food, specify

5. $\square$ Emotions/psychological

6. $\square$ Medication

7. $\square$ I don't know

8. $\square$ Other, specify

17. Would you say the following diseases run in your family?

$\begin{array}{llll}\text { Diabetes } & 1 . \square \text { Yes } & \text { 2. } \square \text { No } & 3 . \square \text { I don't know } \\ \text { Kidney disease } & 1 . \square \text { Yes } & \text { 2. } \square \text { No } & 3 . \square \text { I don't know }\end{array}$


19. Who helps you in taking care of your diabetes/kidney disease (for patients only)?

1. $\square$ Spouse

2. $\square$ Children

3. $\square$ Siblings

4. $\square$ Parents

5. $\square$ Nobody

6. $\square$ Other, please, specify

Subjects' Opinions About Ethical Issues Associated with Participation In FIND/Genetic Family Studies In the FIND study, researchers are trying to identify gene(s) associated with diabetes and kidney disease. Therefore, we will ask you some questions to find out how you might feel about enrolling in the FIND study and inviting relatives to participate.

1. Would you provide information regarding your relatives (prior to obtaining written consent from them) for the purpose of research?
1. $\square$ Yes
2. $\square$ No
3. $\square$ Maybe
4. $\square$ I do not know

2. Which of the following information (about you or your relatives) is acceptable to provide for genetic family study?

1. Health information about physical diseases.

2. Health information about mental diseases.

3. Information such as age, gender and education.

4. Identifiable information such as address, or names.

5. Income.

6. $\square$ Other, specify

$\begin{array}{ll}\square \text { Yes } & \square \text { No } \\ \square \text { Yes } & \square \text { No } \\ \square \text { Yes } & \square \text { No } \\ \square \text { Yes } & \square \text { No } \\ \square \text { Yes } & \square \text { No }\end{array}$

3. Would you say that it is more acceptable to provide information about immediate family members?

If yes, about whom would you provide information?

1. $\square$ Spouse $\square$ brothers $\square$ sisters $\square$ parents $\square$ children

2. $\square$ Extended family members such as cousins

3. $\square$ Everybody in the family

4. $\square$ Other, specify

4. How do you think your relatives will respond to disclosing information about them?
1. $\square$ They won't mind
2. $\square$ Upset
3. $\square$ I don't know
4. $\square$ Other

5. Would you be willing to contact anyone of your relatives and invite him/her to participate in genetic family studies?
1. $\square$ Yes
2. $\square$ No
3. $\square$ Maybe

6. Whom would you contact? (check all possible answers)

1. $\square$ Sibling (s)

2. $\square$ Children

3. $\square$ Parents

4. $\square$ Extended relative

5. $\square$ Nobody

6. $\square$ Anyone

7. Why would you contact your relatives?

1. $\square$ To enhance relatives' awareness of both diabetes and kidney disease

2. $\square$ To support research

3. $\square$ To help future generations

4. $\square$ To learn more about ill relatives

5. $\square$ Other, specify

8. Why you would Not contact your relatives?

1. $\square$ Do not have close family relationship

2. $\square$ Relatives do not live in close proximity

3. $\square$ Relatives are busy

4. $\square$ Relatives are sick

5. $\square$ Relatives have concerns about privacy

6. $\square$ Other, specify

9. Would you say that your relatives might be willing to participate in genetic family studies?
1. $\square$ Yes
2. $\square$ No
3. $\square$ Maybe
4. $\square$ I don't know 
10. Would you prefer that researchers contact your relatives directly?
1. $\square$ Yes
2. $\square$ No
3. $\square$ Does not make a difference

11. Is there any risk(s) associated with providing information about your relatives?
1. $\square$ Yes
2. $\square$ No
3. $\square$ Maybe
4. $\square$ I don't know

12. Is there any benefit(s) from providing information about your relatives?
1. $\square$ Yes
2. $\square$ No
3. $\square$ Maybe
4. $\square$ I don't know

13. How often do you visit with your relatives (such as siblings, parents)? Where do you meet?

14. Do you talk to your relatives or friends about diabetes/diabetic kidney disease in your family?

VI. Closing: Thank you. The information you have furnished will help us to develop better ways to provide care for relatives and patients with diabetes and kidney disease. 